\title{
Investigation of Semi-Active Hydro-Pneumatic Suspension for a Heavy Vehicle Based on Electro-Hydraulic Proportional Valve
}

\author{
Wenchao Yue ${ }^{1}$, Shoucheng $\mathrm{Li}^{2}$, Xiaojun $\mathrm{Zou}^{1}$ \\ ${ }^{1}$ NAVECO Ltd., Nanjing, China \\ ${ }^{2}$ School of Mechanical Engineering, Nanjing University of Science and Technology, Nanjing, China \\ Email: ywc630@126.com
}

How to cite this paper: Yue, W.C., Li, S.C. and Zou, X.J. (2017) Investigation of Semi-Active Hydro-Pneumatic Suspension for a Heavy Vehicle Based on Electro-Hydraulic Proportional Valve. World Journal of Engineering and Technology, 5, 696-706.

https://doi.org/10.4236/wjet.2017.54058

Received: September 26, 2017

Accepted: November 13, 2017

Published: November 16, 2017

Copyright $\odot 2017$ by authors and Scientific Research Publishing Inc. This work is licensed under the Creative Commons Attribution International License (CC BY 4.0).

http://creativecommons.org/licenses/by/4.0/

\begin{abstract}
Hydro-pneumatic suspension is widely used in heavy vehicles due to its nonlinear characteristics of stiffness and damping. However, the conventional passive hydro-pneumatic suspension can't adjust parameters according to the complicated road environment of heavy vehicles to fulfill the requirements of the vehicle ride comfort. In this paper, a semi-active hydro-pneumatic suspension system based on the electro-hydraulic proportional valve control is proposed, and fuzzy control is used as the control strategy to adjust the damping force of the semi-active hydro-pneumatic suspension. A 1/4 semi-active hydro-pneumatic suspension model is established, which is co-simulated with AMESim and MATLAB/Simulink. The co-simulation results show that the semi-active hydro-pneumatic suspension system can significantly reduce vibration of the vehicle body, and improve the suspension performance comparing with passive hydro-pneumatic suspension.
\end{abstract}

\section{Keywords}

Hydro-Pneumatic Suspension, Semi-Active Control, Co-Simulation, Electro-Hydraulic Proportional Valve

\section{Introduction}

The hydro-pneumatic suspension is a special suspension system, which has a large carrying capacity, variable stiffness and variable damping properties compared with the conventional passive suspension [1] and is widely used in heavy vehicles [2]. The hydro-pneumatic suspension applied to heavy vehicles not only has a good vibration isolation [3], ride comfort [4] and handling stability [5], but 
also can adjust the body height to improve the vehicle's ride through [6]. However, the parameters of the conventional passive hydro-pneumatic suspension cannot be adjusted according to the input of the external road surface, so the hydro-pneumatic spring cannot be in the best working condition. The semi-active control method [7] is used to improve the performance of the passive hydro-pneumatic suspension, which is very necessary to improve the ride comfort of the whole vehicle.

This article is based on the hydro-pneumatic suspension of heavy vehicles and build the $1 / 4$ hydro-pneumatic suspension dynamic model. Then, according to the motion state of the suspension, the electro-hydraulic proportional valve is controlled by the fuzzy control method to achieve the adjustment of the hydro-pneumatic spring damping force, so as to improve the ride comfort under different road conditions. The hydraulic servo system is co-simulated with AMESim and MATLAB. The co-simulation results show that the vehicle acceleration is reduced obviously and the ride comfort characteristics are improved comparing with passive hydro-pneumatic suspension.

\section{The Structure and Working Principle of Semi-Active Hydro-Pneumatic Suspension System for Heavy Vehicle}

The structure of a heavy vehicle semi-active hydro-pneumatic suspension system is shown in Figure 1, which shows a two degree of freedom system that represents a model of quarter car. The system consists of two parts, a passive pneumatic suspension and control systems. The dotted line in Figure 1 contains

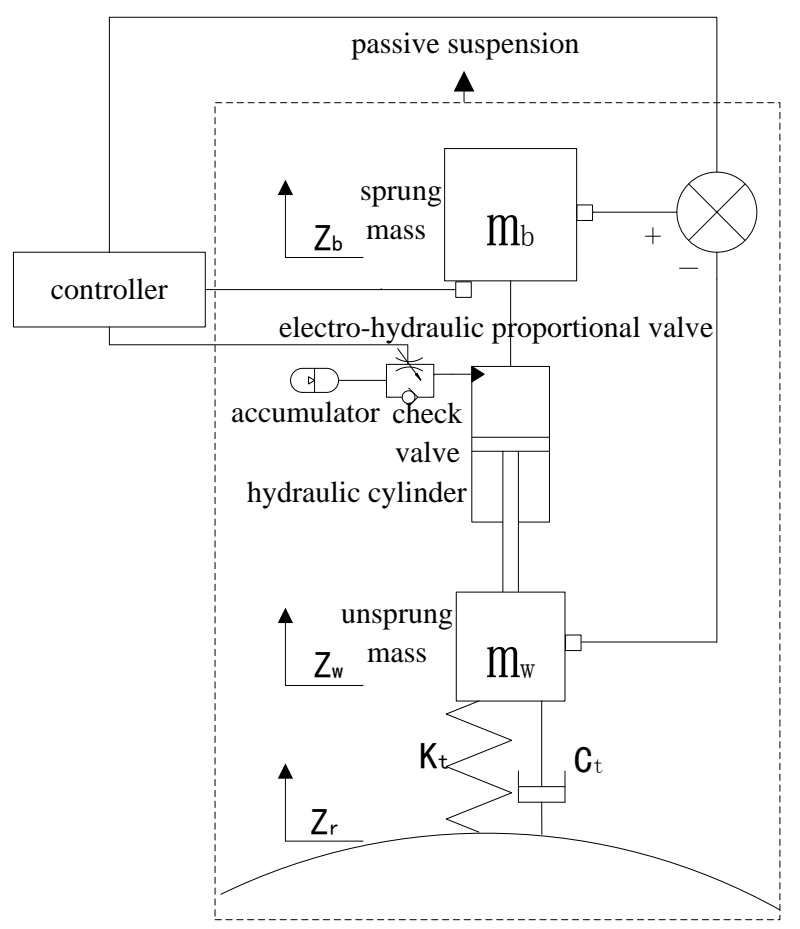

Figure 1. A quarter dynamic model of a heavy vehicle semi-active hydro-pneumatic suspension. 
the passive pneumatic suspension system, and the control section is outside the dashed frame. The semi-active hydro pneumatic suspension uses electro-hydraulic proportional valve to replace the original suspension of the fixed orifice, and the damping force of the hydro pneumatic suspension system is changed by adjusting the spool displacement of the electro-hydraulic proportional valve. In Figure 1: $m_{b}$ and $m_{w}$ are the sprung mass and the unsprung mass respectively, $k_{t}$ and $c_{t}$ are the tire stiffness and the tire damping respectively, $Z_{r}, Z_{w}$ and $z_{b}$ are the displacements for road disturbance, unsprung mass and sprung mass respectively.

In this paper, the working principle of semi-active hydro-pneumatic suspension is as follows: using the suspension working space and the acceleration of the sprung mass as feedback signal, and established in accordance with the deviation of the negative feedback controller, and then use the fuzzy algorithm regulating the valve opening of electro-hydraulic proportional to achieve a controllable hydro-pneumatic spring damping force. The electro-hydraulic proportional valve is connected directly to the actuator that is the cylinder of hydro-pneumatic spring.

\section{Semi-Active Suspension Modeling of Hydro-Pneumatic Suspension}

\subsection{Hydro-Pneumatic Spring Model}

In this paper, the hydro-pneumatic spring of heavy vehicles is mainly composed of accumulator and hydraulic cylinder, the hydraulic cylinder is equipped with damping hole and check valve, the physical model is shown in Figure 2. The hydro-pneumatic spring is based on the inert gas (usually nitrogen) as the elastic medium, and the oil as the transfer medium, It eases ground shock by compressed gas (equivalent to the conventional spring suspension), and it attenuates the vibration of vehicles by the oil flowing through the orifice, thereby generating the damping force (equivalent to the traditional suspension shock absorber).

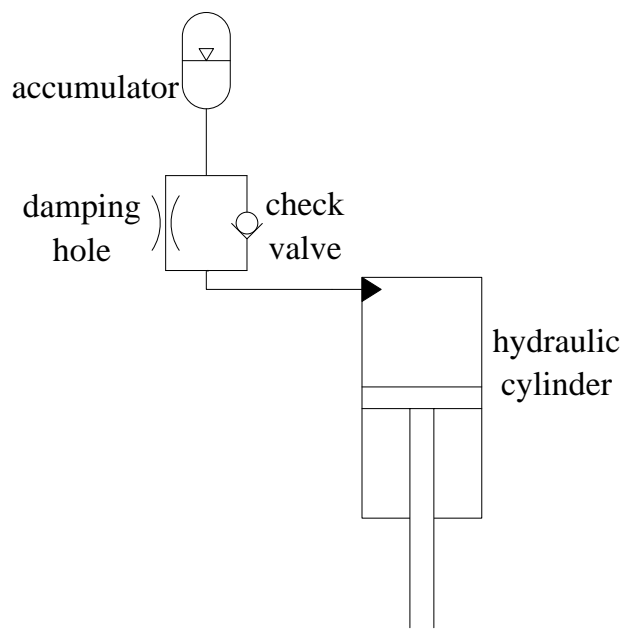

Figure 2. Physical model of hydro-pneumatic suspension. 
Meanwhile, the compression stroke is different from the damping force of the recovery stroke because of the check valve.

When the piston rod is subjected to the action of the displacement excitation signal, the instantaneous pressure of the gas in the accumulator is obtained by the gas adiabatic equation:

$$
P_{g} V_{g}^{n}=P_{g 0} V_{g 0}^{n}
$$

where: $P_{g 0}, V_{g 0}$ are the gas pressure and the volume of the accumulator at the equilibrium position, $P_{g}, V_{g}$ are instantaneous gas pressure and volume of the accumulator, $n$ is the gas variable index.

Assuming that the displacement of the compression stroke of the hydro-pneumatic spring is positive, the instantaneous gas volume of the accumulator can be expressed as:

$$
V_{g}=V_{g 0}-A_{c} Z
$$

where: $A_{c}$ is the effective area of the piston, $z$ is the displacement of the hydropneumatic spring.

In the hydro-pneumatic spring system, the throttle orifice (damping hole and check valve) is the main structure of the damping force. According to the theory of thin-walled aperture [8], the pressure difference of the throttle orifice can be expressed as:

$$
\Delta P_{\text {damper }}=\frac{1}{2} \rho\left[A_{c} \dot{z} / C_{d}\left\{S_{1}+S_{2}[1+\operatorname{sign}(\dot{z})] / 2\right\}\right]^{2} \operatorname{sign}(\dot{z})
$$

where: $\rho$ is fluid density, $C_{d}$ is discharge coefficient, $S_{1}$ is the area of the orifice, $S_{2}$ is the area of the check valve, $\dot{Z}$ is the speed of the excitation signal.

The force of the hydro-pneumatic suspension system consists of three parts: damping force, elastic force and friction force. Normally, the lubrication between the piston and the cylinder wall is good, so the friction force can be ignored. The force of piston can be expressed as follows:

$$
F=P_{c} A_{c}
$$

where: $P_{c}$ is the pressure of hydraulic cylinder, $F$ is the force of the piston rod, and $P_{c}=P_{g}+\Delta P_{\text {damper }}$.

In order to verify the correctness of the above hydro-pneumatic spring model, the performance of the hydro-pneumatic spring is tested and compared with the simulation results. The bench test is shown in Figure 3.

The bench test includes two parts: static test and dynamic test. Static test is the relationship between $F$ and $z$ in the static state of the hydro-pneumatic spring under a certain initial inflation pressure. Dynamic test is the use of sinusoidal excitation signal to measure the relationship between the $F$ and $z$, which is applied to the piston rod. Figure 4 shows the simulation and test curves for the static characteristics of the hydro-pneumatic springs. Figure 5 is the simulation and experimental curves for the dynamic characteristics of the hydro-pneumatic spring under the conditions of sine excitation (frequency $1.25 \mathrm{~Hz}$, amplitude 30 $\mathrm{mm})$. 


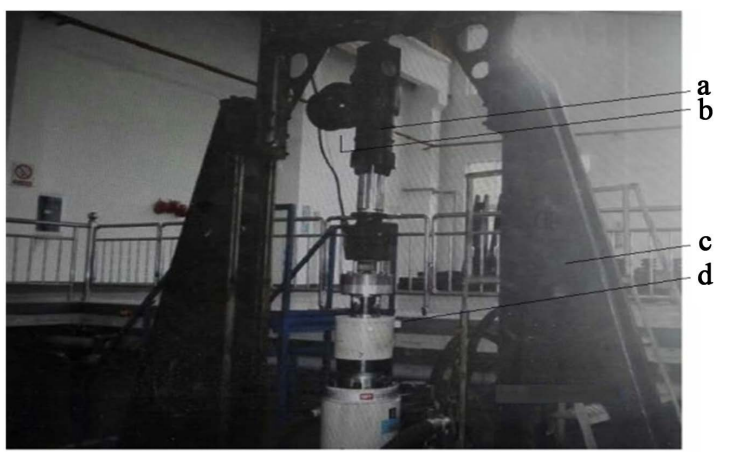

Figure 3. Bench test of the characteristics of hydro-pneumatic suspension: a-hydraulic cylinder, $\mathrm{b}$-accumulator, $\mathrm{c}$ - test bench, $\mathrm{d}$-hydraulic actuator.
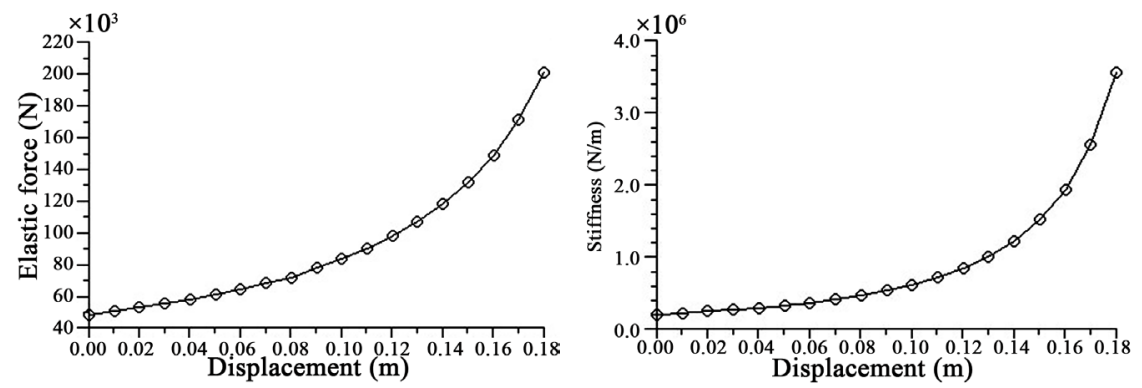

Figure 4. Static characteristics of hydro-pneumatic spring.
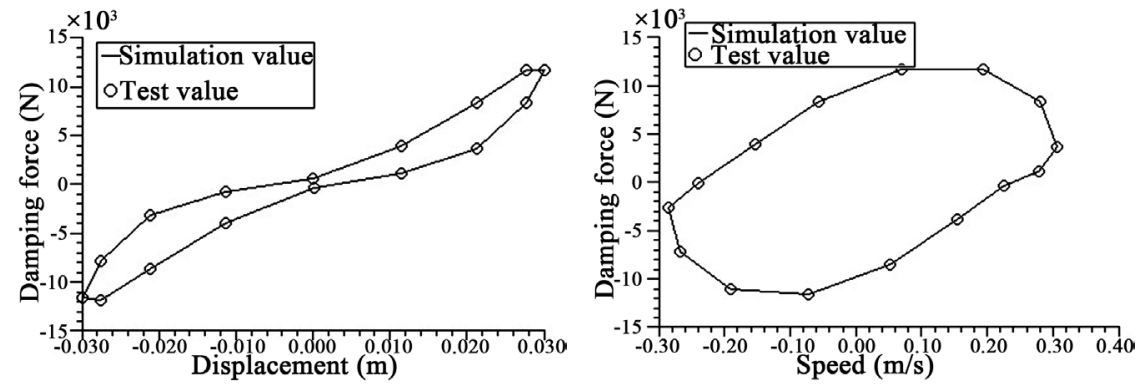

Figure 5. Dynamic characteristics of hydro-pneumatic spring.

\subsection{Nonlinear Model of Semi-Active Hydro-Pneumatic Suspension}

The dynamic model of semi-active hydro-pneumatic suspension is shown in Figure 1. According to Newton second law and analyzed the expression (1)-(4), the relationship between the force of the piston rod and the excitation signal can be expressed as:

$$
\left\{\begin{array}{l}
m_{b} \ddot{z}_{b}=F \\
m_{w} \ddot{z}_{w}=-F+k_{t}\left(z_{r}-z_{w}\right)+c_{t}\left(\dot{z}_{r}-\dot{z}_{w}\right) \\
F=d\left(\dot{z}_{b}-\dot{z}_{w}\right)+k_{2}\left(z_{b}-z_{w}\right)
\end{array}\right.
$$

where: $d$ is the variable damping of the hydro-pneumatic suspension system, $k_{2}$ is the variable stiffness of the hydro-pneumatic suspension system.

The state vector is $z, \quad z=\left[\begin{array}{lllll}z_{b} & z_{b}-z_{w} & \dot{z}_{b} & \dot{z}_{w}\end{array}\right]^{\mathrm{T}}$, the system output is $Y$, $Y=\left[\begin{array}{llll}z_{b} & z_{b}-z_{w} & k_{t}\left(z_{r}-z_{w}\right)\end{array}\right]^{\mathrm{T}}$, the system input is the road roughness excitation, 
the state space expression of the suspension system is made by the motion differential equation:

$$
\left\{\begin{array}{l}
\dot{Z}=A Z+B U \\
Y=C Z+D U
\end{array}\right.
$$

where: $A$ is the system matrix, $B$ is the input (control) matrix, $C$ is the output matrix, $D$ is a direct transfer matrix.

$$
\begin{aligned}
& A=\left(\begin{array}{cccc}
0 & 0 & 1 & 0 \\
0 & 0 & -1 & 1 \\
\frac{-k_{t}}{m_{w}} & \frac{k_{2}}{m_{w}} & \frac{-d}{m_{w}} & \frac{d}{m_{w}} \\
0 & \frac{-k_{2}}{m_{b}} & \frac{d}{m_{b}} & \frac{d}{m_{w}}
\end{array}\right), \\
& B=\left(\begin{array}{c}
0 \\
0 \\
\frac{k_{t}}{m_{w}} \\
0
\end{array}\right), \\
& C=\left(\begin{array}{cccc}
0 & \frac{-k_{2}}{m_{2}} & \frac{d}{m_{2}} & \frac{-d}{m_{2}} \\
0 & 1 & 0 & 0 \\
k_{t} & 0 & 0 & 0
\end{array}\right), \\
& D=\left(\begin{array}{r}
0 \\
0 \\
-k_{w}
\end{array}\right)
\end{aligned}
$$

\section{Design of Fuzzy Controller}

Fuzzy control does not require a precise mathematical model, as long as the input and output data based on the actual system, refer to the operation experience and expert experience, and then the system can be real-time control. In this paper, fuzzy control is shown in Figure 6.

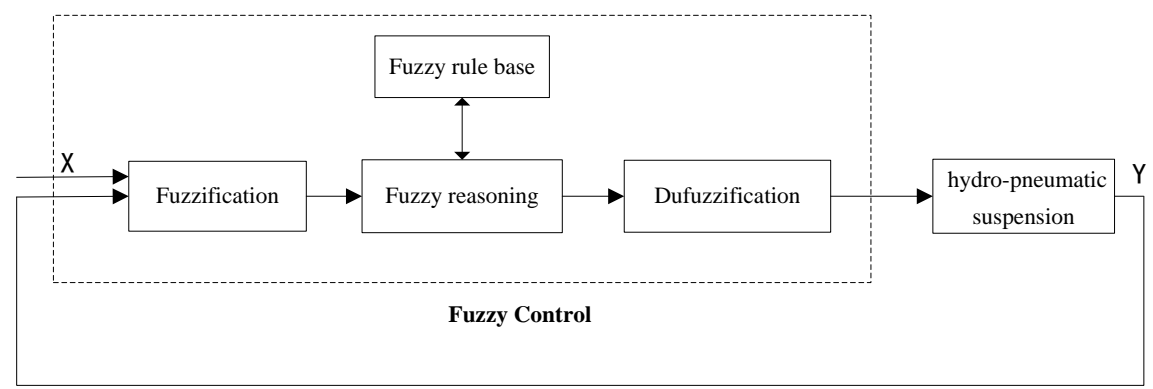

Figure 6. Structure diagram of fuzzy controller. 
In Figure 6, the control object is the hydro-pneumatic suspension system, the input of its fuzzy controller is the body acceleration and suspension relative displacement, and the output is the spool displacement of electric hydraulic proportional valve. $X$ and $Y$ represent the body acceleration and suspension relative displacement.

Considering the fuzzy controller with two inputs and one output, if the output of the hydro pneumatic suspension system is $Y, Y=\left[\begin{array}{lll}z_{b} & z_{b}-z_{w}\end{array}\right]^{\mathrm{T}}$. At the same time, the state equation of the system is not changed, and the output equation of the system is unchanged. $C$ and $D$ is still the output and direct transfer matrix. At this time, $C=\left(\begin{array}{cccc}0 & \frac{-k_{2}}{m_{b}} & \frac{d}{m_{b}} & \frac{-d}{m_{b}} \\ 0 & 1 & 0 & 0\end{array}\right), D=\left(\begin{array}{l}0 \\ 0\end{array}\right)$.

In the fuzzy controller of the semi-active suspension, e and ec are both $[-6,6]$, the valve spool displacement of the domain are $[0,10]$. Among them, two input e, ec and one output are defined as seven fuzzy subsets of PB PM PS Z NS NM NB. The membership function of the output variable is the same as the input error and error rate of change, both with a triangular membership function.

According to the amount of fuzzy sets and membership functions, fuzzy rule table of fuzzy output variables can be deduced by MAX-MIN fuzzy inference after fuzzification. The fuzzy control rules are established by the empirical induction method, and the self-tuning fuzzy control rules of the output displacement are shown in Table 1 [9].

The fuzzy output is obtained by the fuzzy rules in Table 1 , and the parameters can be obtained by the inverse model, so that the control of the hydro-pneumatic suspension system can be realized.

\section{Co-Simulation of Semi-Active Hydro-Pneumatic Suspension}

Use the co-simulation of MATLAB/Simulink and AMESim to verify the effectiveness of the control algorithm used in this paper. Step signal and a filtered white noise are used as the road input model. Filter white noise to the road surface model [10] is:

Table 1. Fuzzy control of output displacement.

\begin{tabular}{cccccccc}
\hline ec & $N B$ & $N M$ & $N S$ & $Z$ & $P S$ & $P M$ & $P B$ \\
\hline$N B$ & $P B$ & $P B$ & $P M$ & $P M$ & $P S$ & $P S$ & $Z$ \\
$N M$ & $P B$ & $P B$ & $P M$ & $P M$ & $P S$ & $Z$ & $Z$ \\
$N S$ & $P M$ & $P M$ & $P M$ & $P S$ & $Z$ & $N S$ & $N M$ \\
$Z$ & $P M$ & $P S$ & $P S$ & $Z$ & $N S$ & $N M$ & $N M$ \\
$P S$ & $P S$ & $P S$ & $Z$ & $N S$ & $N S$ & $N M$ & $N M$ \\
$P M$ & $Z$ & $Z$ & $N S$ & $N M$ & $N M$ & $N M$ & $N B$ \\
$P B$ & $Z$ & $N S$ & $N S$ & $N M$ & $N M$ & $N B$ & $N B$ \\
\hline
\end{tabular}




$$
\dot{q}=-2 \pi f_{0} q+2 \pi \sqrt{G_{0} u} w(t)
$$

where: $G_{0}$ is the road roughness coefficient, $\mathrm{u}$ is the vehicle speed, $f_{0}$ is the lower cut-off frequency, $w(t)$ is the Gauss white noise with the expected value of zero. The simulation input parameters of the heavy vehicle are shown in Table 2.

The semi-active suspension and passive suspension of hydro-pneumatic are simulated and analyzed. Figure 7 is a random road input displacement curve, Figure 8 is a step road input curve, Figure 9 is the simulation results for the sprung mass acceleration of passive suspension, Figure 10 shows the simulation results for the sprung mass of semi-active hydro-pneumatic suspension, Figure 11 and Figure 12 are both sprung mass acceleration simulation results, which are simulated under the step road.

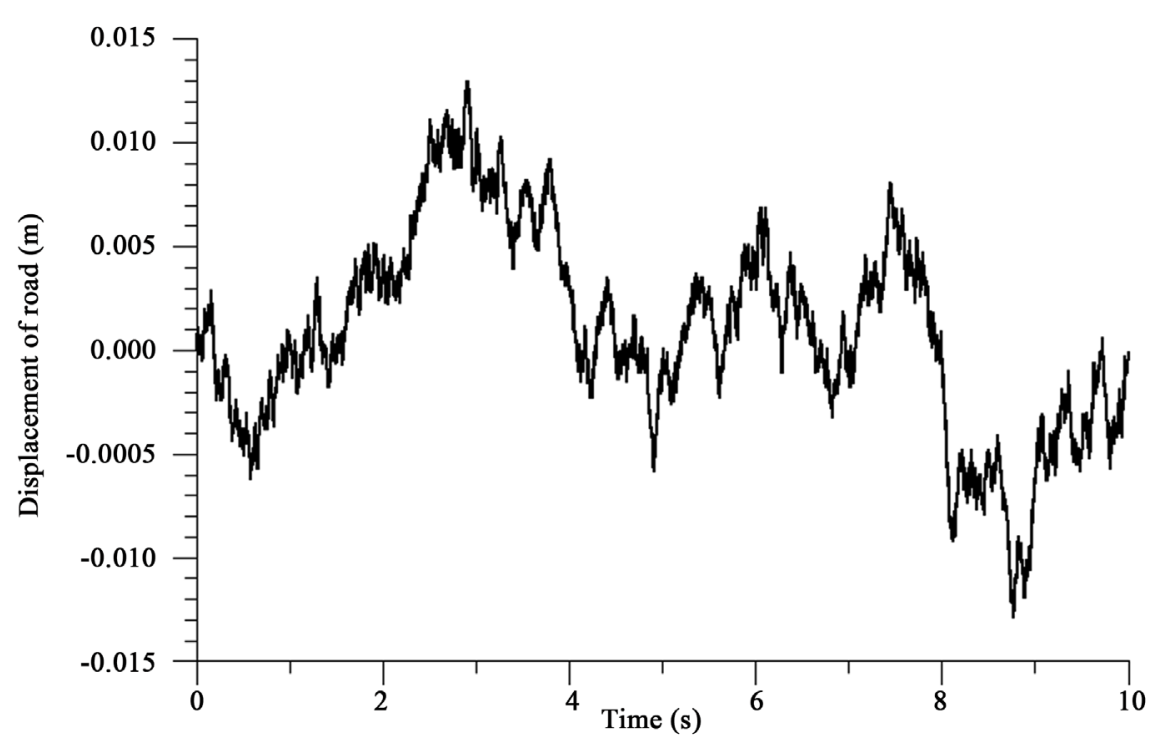

Figure 7. Road random input.

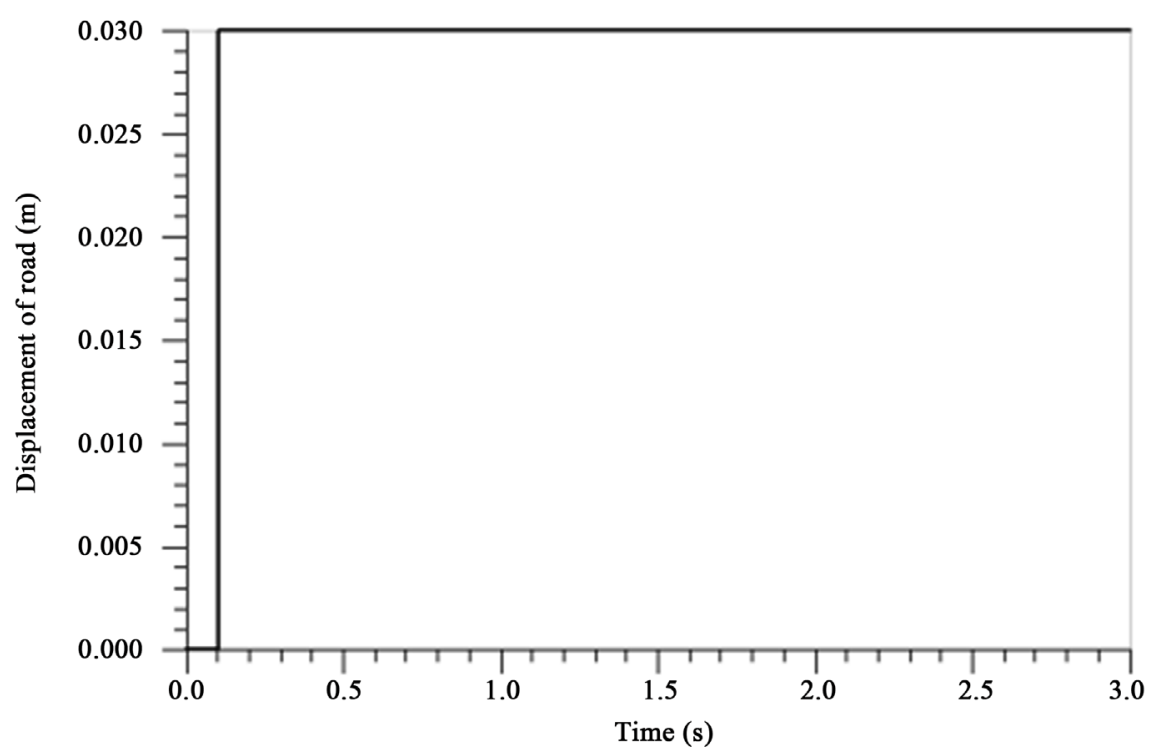

Figure 8. Step road. 


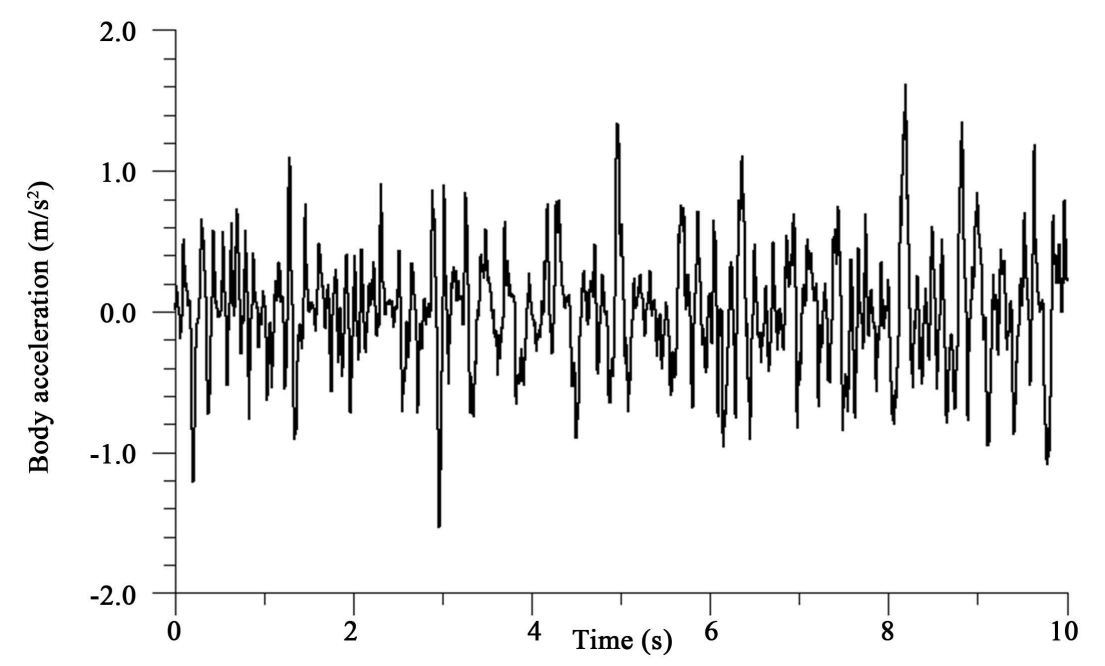

Figure 9. Body acceleration of passive suspension.

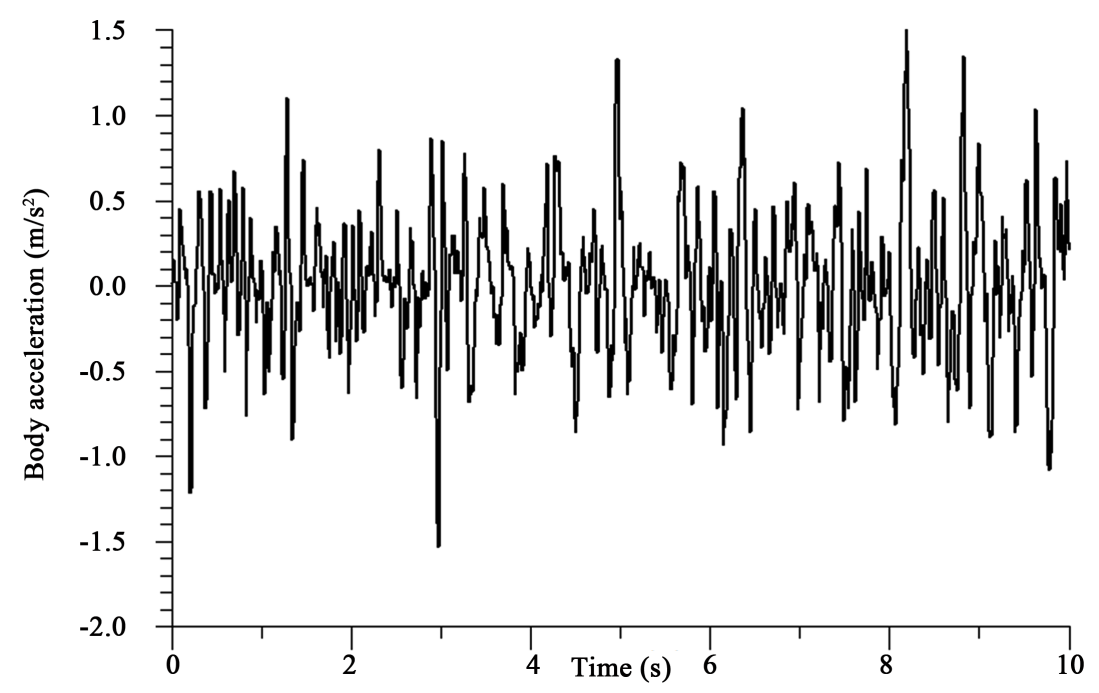

Figure 10. Body acceleration of semi-active suspension.

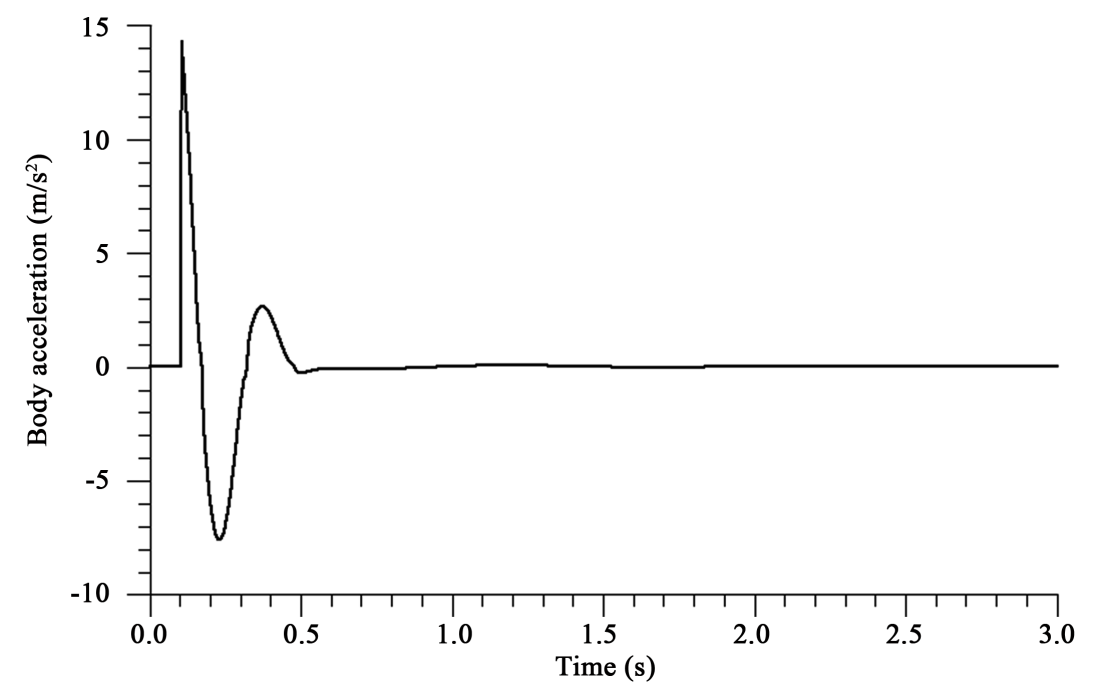

Figure 11. Body acceleration of passive suspension under step road. 


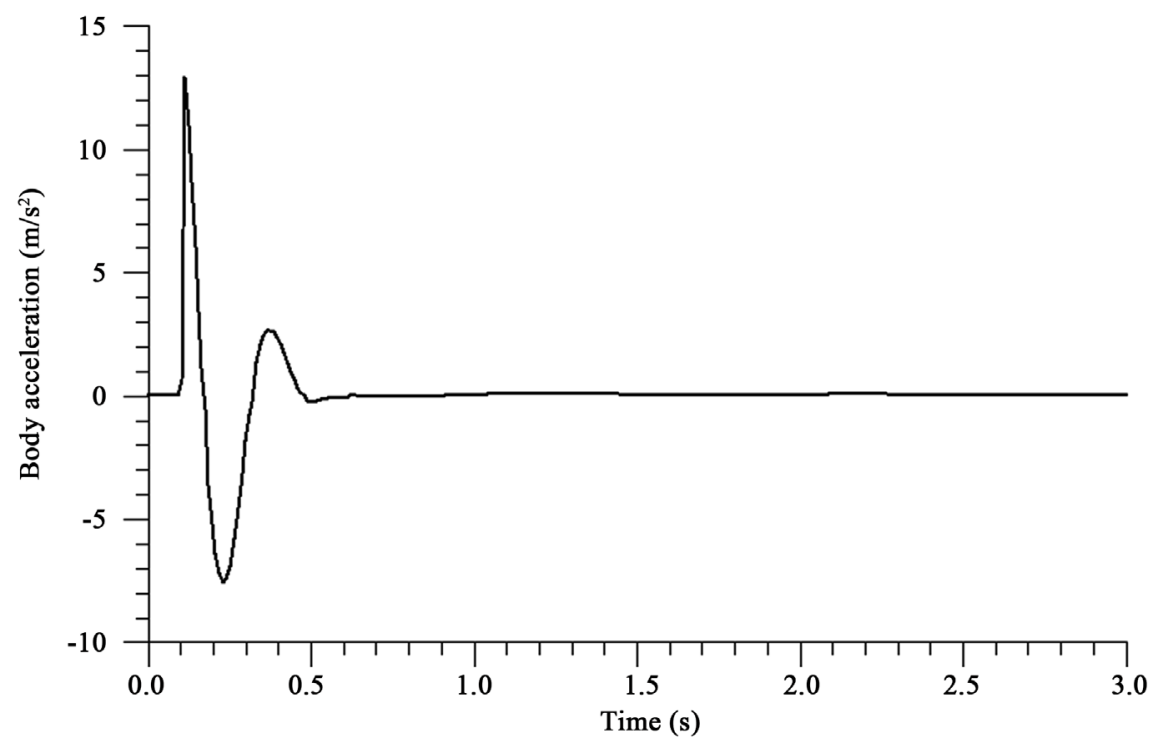

Figure 12. Body acceleration of semi-active suspension under step road.

Table 2. Heavy vehicle simulation input parameters.

\begin{tabular}{cc}
\hline Parameter & Value \\
\hline Sprung mass $m_{b}$ & $4900(\mathrm{~kg})$ \\
Unsprung mass $m_{w}$ & $724(\mathrm{~kg})$ \\
Tyre stiffness $k_{t}$ & $2.65 \mathrm{e} 6(\mathrm{kN} / \mathrm{m})$ \\
Road roughness coefficient $G_{0}$ & $16 \times 10^{-6}\left(\mathrm{~m}^{3} / \mathrm{cycle}\right)$ \\
Lower cut-off frequency $f_{o}$ & $0.1(\mathrm{~Hz})$ \\
Vehicle speed $u$ & $16.7(\mathrm{~m} / \mathrm{s})$ \\
\hline
\end{tabular}

As can be seen from Figures 9-12, the simulation results for the sprung mass of semi-active hydro-pneumatic suspension is better than that of passive suspension. After calculation, compare the sprung mass acceleration RMS value of semi-active hydro-pneumatic suspension with passive suspension under the random road excitation, which is reduced from $0.42 \mathrm{~m} / \mathrm{s}^{2}$ to $0.32 \mathrm{~m} / \mathrm{s}^{2}$. The peak acceleration of the vehicle body with semi-active hydro-pneumatic suspension is obviously decreased; the sprung mass peak acceleration of the semi-active suspension is reduced by $1 \mathrm{~m} / \mathrm{s}^{2}$ under the step road excitation.

\section{Conclusion}

In this paper, the nonlinear model of the hydro-pneumatic suspension of the heavy vehicle has been established, which was based on the modeling and verification. The electro-hydraulic proportional valve was controlled by fuzzy method so that the damping force of the hydro-pneumatic suspension was adjusted; the control effect of the semi-active hydro-pneumatic suspension was studied by the co-simulation of MATLAB/Simulink and AMESim. The simulation results showed that the sprung mass acceleration RMS value of the semi-active hy- 
dro-pneumatic suspension relative to the passive hydro pneumatic suspension was reduced about $24 \%$ under the random road excitation; the peak acceleration of the semi-active hydro-pneumatic suspension is obviously decreased under the step excitation. The semi-active hydro-pneumatic suspension designed in this paper can effectively improve the ride comfort of the vehicle and improve the comfort of the vehicle.

\section{References}

[1] Sun, T., Zhang, Z.D., Yu, F., et al. (2007) Analysis of the Effects of Uncertainties on Robustness for a Hydro-Pneumatic Suspension Closed-Loop System. Journal of Vibration and Shock, 26, 18-22.

[2] Cao, S.P., Yi, M.L. (2002) Research on the Nonlinear Mathematical Model of the Hydro-Pneumatic Suspension for Heavy Off-Road Vehicle. Mechanical Science and Technology for Aerospace Engineering, 21, 979-980.

[3] Moulton, A.E. Best Hydrogas suspension. SAE 790374: 1307-1329.

[4] Zhou, D.C., Wang, G.Q., Liu, Y.C., et al. (2004) Effects of Parameters of Hydro-Pneumatic Suspension Cylinder on Vehicle Ride Comfort. Transactions of the Chinese Society for Agricultural Machinery, 35, 25-28.

[5] Sun, B.B., Zhou, C.F., Zhang, X.Y., et al. (2007) Nonlinear Dynamic Characteristics of Rubber Suspension of Construction Vehicle. Journal of Southeast University, 37, 974-979.

[6] Giliomee, C.L. and Els, P.S. (1998) Semi-Active Hydropneumatic Spring and Damper System. Journal of Terramechanics, 35, 109-117.

[7] Wang, D.L., Guan, J.F. and Wang, W.R. (2009) Fuzzy Control System for Semi-Active Hydro-Pneumatic Suspension. Transactions of the Chinese Society for Agricultural Machinery, 40, 23-26.

[8] Lee, K. (1997) Numerical Modeling for the Hydraulic Performance Prediction of Automotive Monotube Dampers. Vehicle System Dynamics, 28, 25-39. https://doi.org/10.1080/00423119708969347

[9] Ding, S.G., LU, J.B., et al. (2007) The Simulation and Application Study on the Hydraulic Press Servo System Based on High Precision Fuzzy Control Arithmetic in Straightening Machine. Heavy Machinery, 15, 23-25.

[10] Xu, Y.H. (2007) Computer Simulation on Stochastic Road Irregularities. Transactions of the Chinese Society for Agricultural Machinery, 38, 33-36. 